\section{Response to: 'Is it currently reasonable to offer short 14-day antibiotic therapies after a surgical synovectomy in native joint septic arthritis?' by Coiffier et al}

We read with great interest the (mostly justified) scientific remarks of our colleagues Coiffier et $a l^{1}$ to our article, ${ }^{2}$ randomising to either 2 or 4 weeks of systemic targeted antibiotic therapy after surgical drainage of native joint bacterial arthritis in adults. This was a classical non-inferiority trial detecting a similar outcome, similar mechanical sequels and a similar proportion of antibioticrelated adverse events in the short-antibiotic treatment group when compared with the classical long antibiotic administration of 4 weeks. $^{2}$

However, native joint septic arthritis is a very heterogeneous group of clinical entities with different epidemiological, microbiological and therapeutic aspects in humans. The spectrum varies between adult and paediatric patients, with and without concomitant adjacent osteomyelitis or immune suppression, pathogens (Staphylococcus aureus, Pseudomonas aeruginosa, gonococci, viruses), anatomical localisations (extremities, hand, diabetic foot, spine, mandibular, shoulder, sacroiliac), settings (orthopaedic departments vs rheumatological services), origins (spontaneous, intravenous drug abuse, surgical site infections, post-traumatic, bites) and management (surgeons, rheumatologists, internists, emergency vs elective drainage). ${ }^{3}$

Of note, our trial accepted all surgically drained arthritis cases but was sufficiently powered for the overall population plus the subgroup of hand and wrist arthritis cases, which in turn were mostly traumatic in origin occurring in young, healthy and immune-competent adults. Regarding the overall population, and the hand subpopulation, these non-inferiority requirements were fulfilled. For other subgroups it was not, because each of the aforementioned subgroups would formally require at minimum 100-150 randomised cases to be statistically correct; and maybe also separate trials. Our colleagues Coiffier et al equally acknowledge this inherent shortcoming of every arthritis trial in general. ${ }^{1}$ Probably they work with a high burden of spontaneous arthritis cases in large joints that they treat (initially) by arthrocentesis and systemic antibiotic therapy? This would be indeed a different setting.

As Coiffier et al, ${ }^{1}$ we explicitly avoid to conclude that every native joint septic arthritis should be treated only during 14 days of systemic antibiotic therapy. ${ }^{2}$ But we reveal the feasibility and the worth of investigating of such an approach; nota bene because we did not detect any inconvenient during an active and prospective follow-up. In contrast, regarding surgically drained hand arthritis episodes due to 'classical' bacteria (eg, no mycobacteria), ${ }^{4}$ we encourage the international community to shorten their individual current durations to 14 days; at least to try it and to gain own experience. With retrospective ${ }^{56}$ and now prospective data on its favour, ${ }^{2}$ there is no reason to wait any longer for septic hand arthritis cases.

For other localisation and origins, for example, spontaneous primary hip and knee arthritis, specific follow-up trials can be encouraged (along with other trials such as the concomitant add-on of systemic steroids or other anti-inflammatory medications in adults; or a comparison between rheumatological (iterative) arthrocentesis vs surgical drainage, for example). ${ }^{7}$

Additionally, Coiffier et al ask for some issues that were not fully discussed. For example, they advocate that the minimal follow-up time for every osteoarticular infection should be
1 year, that the sample size calculation should be higher because of more expected recurrences (among large joint infections) and that the per-protocol analysis should be displayed for the overall population (instead of the subgroup of hand arthritis cases). Finally, they mention that follow-up radiographies were not performed in every study participants.

While we fully agree with a minimal follow-up of 2 years for implant-related bone infections (that is equally promoted by surveillance authorities all over the word), the situation is less clear for implant-free bone and joint infections. Analogy is difficult, because osteomyelitis can clinically recur lifelong (up to 40 years), ${ }^{8}$ even if reviewers usually accept a surveillance period of 1 or 2 years for practical reasons. We agree with that.

In contrast, we beg to differ regarding the the follow-up time for a surgically drained septic arthritis without osteitis. Indeed, we are unaware of any scientific data pushing for a follow-up time of 1 year for $S$. aureus or streptococcal septic arthritis in its pure form. As reviewers of other papers, according to our ethical committee, our own experience and that of international experts, septic arthritis recurrences occur much more rapidly. Personally, we, for example, ignore own cases with any streptococcal arthritis recurrences at 11, or even 5 months, unless there has been a new episode of joint infection. As experts in this field, we must not promote confounding bone and implant infections with joints. We should not apply bone criteria for joints. These are different entities, even if the international community tends to resume 'osteo' and 'articular' within one single breath. Finally, our study criteria only required a minimal follow-up of 2 months officially (regarding infection). In reality, our median follow-up was 2.2 years (IQR, 1.6-2.8 years) ${ }^{2}$ and rather motivated by sequels than mere recurrent infections. Regarding infections, the recurrence delays in our centre (where this single-centre study stems from) justify our non-inferiority calculations.

We performed control radiographies only if there were anamnestic and/or clinical reasons and avoided additional costs and consultations; only for study purposes. We were not interested to detect a silent radiological secondary osteoarthritis without clinical consequences. Lastly, Coiffier et al criticise to sum up every kind of arthritis cases in one analysis but advocate doing so in an overall per-protocol analysis. We might interpret this as contradiction. In this sense, we were more purists by keeping the per-protocol analysis for the subgroup of hand arthritis only, for which we are 'formal' in reducing the antibiotic duration. ${ }^{12}$

Overall, we thank our academic and specialised French colleagues ${ }^{1}$ to recall the shortcomings of our trial, ${ }^{2}$ which obviously cannot be fully displayed in the frame of a regular article.

Ilker Uçkay $\odot,{ }^{1}$ Amanda Gonzalez, ${ }^{2}$ Ergys Gjika ${ }^{2}$
${ }^{1}$ Infectiology, Uniklinik Balgrist, Zurich, Switzerland
${ }^{2}$ Hand Surgery Unit, Geneva University Hospitals, Geneva, Switzerland

Correspondence to Dr Ilker Uçkay, Uniklinik Balgrist, Zurich 8008, Switzerland; ilker.uckay@balgrist.ch

Handling editor Josef S Smolen

Contributors IU: writing. AG: writing and concept. EG: writing, practical issues and clinics.

Competing interests None declared.

Patient consent for publication Not required.

Provenance and peer review Commissioned; internally peer reviewed.

(c) Author(s) (or their employer(s)) 2020. No commercial re-use. See rights and permissions. Published by BMJ.

Check for updates

To cite Uçkay I, Gonzalez A, Gjika E. Ann Rheum Dis 2020;79:e147. 
Received 21 June 2019

Accepted 22 June 2019

Published Online First 5 July 2019

\section{(S) Linked}

http://dx.doi.org/10.1136/annrheumdis-2019-215887

Ann Rheum Dis 2020;79:e147. doi:10.1136/annrheumdis-2019-215905

ORCID iD

Ilker Uçkay http://orcid.org/0000-0002-5552-0973

\section{REFERENCES}

1 Coiffer G, Couderc M, Seror R, et al. Is it currently reasonable to offer short 14-day antibiotic therapies after a surgical synovectomy in native joint septic arthritis? Ann Rheum Dis 2020;79:e146.
2 Gjika E, Beaulieu J-Y, Vakalopoulos K, et al. Two weeks versus four weeks of antibiotic therapy after surgical drainage for native joint bacterial arthritis: a prospective, randomised, non-inferiority trial. Ann Rheum Dis 2019;78:1114-21.

3 Lauper N, Davat M, Gjika E, et al. Native septic arthritis is not an immediate surgical emergency. J Infect 2018;77:47-53.

4 Balagué N, Uçkay I, Vostrel P, et al. Non-tuberculous mycobacterial infections of the hand. Chir Main 2015;34:18-23.

5 Meier R, Wirth T, Hahn F, et al. Pyogenic Arthritis of the Fingers and the Wrist: Can We Shorten Antimicrobial Treatment Duration? Open Forum Infect Dis 2017:4.

6 Uçkay I, Tovmirzaeva L, Garbino J, et al. Short parenteral antibiotic treatment for adult septic arthritis after successful drainage. Int J Infect Dis 2013;17:e199-205.

7 Debrach A-C, Lazarou I, Gabay C, et al. [Management of septic arthritis]. Rev Med Suisse 2018;14:516-21.

8 Uçkay I, Assal M, Legout L, et al. Recurrent osteomyelitis caused by infection with different bacterial strains without obvious source of reinfection. J Clin Microbiol 2006;44:1194-6. 